\title{
Suppression of Soil Dilation-A Reinforcing Mechanism of Soil-Geosynthetic Composites
}

\author{
Jonathan T. H. Wu • Kuo-Hsin Yang • \\ Suliman Mohamed • Thang Pham • Rong-Her Chen
}

Accepted: 20 January 2014 / Published online: 15 February 2014

(C) Springer New York 2014

\begin{abstract}
The presence of geosynthetic reinforcement in soil mass has been shown to reduce the tendency of dilation of the soil when subject to shear stress, especially when the reinforcement is closely spaced. As tensile loads are induced in geosynthetic reinforcement, adjacent reinforcement layers tend to act as tensioned membranes that inhibit dilation of the soil enclosed between the reinforcement layers. The suppression of soil dilation leads to stronger soil and is regarded as a reinforcing mechanism. This paper presents for the first time measured volume change behavior of field-scale experiments on reinforced and unreinforced soils. The volume change behavior, as characterized quantitatively by the angle of dilation, is presented and discussed. This paper also describes finite element analysis for the stress-strain and volume change behavior of field-scale soil-geosynthetic composites. Using the calibrated finite element model, a parametric study was conducted to examine the effects of reinforcement spacing, reinforcement stiffness, and soil stiffness on volume change behavior of soil-geosynthetic composites. The measured data and finite element analysis results
\end{abstract}

J. T. H. Wu ( ()

Reinforce Soil Research Center, University of Colorado Denver, Denver, CO 80217, USA

e-mail: jonathan.wu@ucdenver.edu

K.-H. Yang

Department of Construction Engineering, National Taiwan University of Science and Technology, Taipei, Taiwan

e-mail: khy@mail.ntust.edu.tw

S. Mohamed

Department of Engineering Science, University of Nyala, Nyala, Sudan

e-mail: kobrest@yahoo.com

T. Pham

Ministry of Construction, Institute of Geotechnical Engineering (IGE/IBST), Hanoi, Socialist Republic of Vietnam

e-mail: phamthangibst@gmail.com

R.-H. Chen

Department of Civil Engineering, National Taiwan University, Taipei, Taiwan

e-mail: rongherchen@ntu.edu.tw 
suggest that the mechanism of suppression of soil dilation (addresses volume change behavior), and the mechanisms of apparent confining pressure and apparent cohesion (two popular mechanisms that address strength behavior) are likely independent.

Keywords Reinforced soil · Geosynthetics · Reinforcing mechanism · Volume change · Finite element analysis $\cdot$ Angle of dilation

\section{Introduction}

Reinforced soil walls and steepened slopes with geosynthetics as reinforcement have seen increasing applications in earthwork construction around the world. Reinforcement spacing of 0.3 to $1.0 \mathrm{~m}$ has commonly been employed in construction. However, the benefits of closely spaced reinforcement did not go unnoticed and have been demonstrated through many field-scale experiments, where the reinforcement spacing replicates those in actual construction (e.g., [2, 10, 22, 27, 33]). When reinforcement spacing is kept small (say, $0.3 \mathrm{~m}$ or smaller), the reinforced soil mass is seen to exhibit significant reinforcing effects (in addition to just being a tension resistance member), and its behavior can be characterized as that of a composite [30]. Following the definition given by the Federal Highway Administration (FHWA) [3, 4], a soil mass reinforced by layers of geosynthetic sheets at a spacing of $\leq 0.3 \mathrm{~m}$ is referred to as geosynthetic-reinforced soil (GRS), although the term has sometimes been used in the literature to denote reinforced soil systems with geosynthetic reinforcement at any spacing. GRS has recently been implemented in the design and construction of bridge abutments by the FHWA. The system is known as geosynthetic reinforced soilintegrated bridge system (GRS-IBS) [3, 4]. Since its introduction in 2011, over 100 GRS-IBS have been constructed in the USA.

Several mechanisms by which geosynthetic reinforcement contributes to the increase in strength and/or stiffness of soil have been proposed [5-7, 10, 11, 14, 16, 20, $22,25,32]$. Among them, two mechanisms involve quantitative evaluation of the reinforcing effects. One was proposed by Schlosser and Long [25], where the presence of geosynthetic reinforcement is said to give the soil an added anisotropic cohesion and results in an "apparent cohesion." The other, proposed by Yang [32], considers that the geosynthetic reinforcement increases effective confinement of the soil. The increase in confinement is referred to as "apparent confining pressure."

In this paper, a third mechanism with quantitative evaluation of reinforcing effectsuppression of soil dilation - is addressed by examining measured behavior of fieldscale experiments and by finite element (FE) analysis. The behavior of suppressing soil dilation has been noted by Haeri et al. [12] using small triaxial tests with and without geosynthetic disks in test specimens. The tests showed a decrease in soil dilation with inclusion of geosynthetic disks, but dilation was still prevalent in all test specimens, even at extremely small reinforcement spacing.

This paper begins with a general description of the volume change behavior of unreinforced and reinforced soil. The need for field-scale experiments is discussed, and the volume change behavior of four field-scale experiments on "representative" soilgeosynthetic composites are presented, followed by finite element calibration and a parametric analysis of the volume change behavior. The parametric study was carried 
out to examine the effects of reinforcement spacing, reinforcement stiffness, and soil stiffness on volume change behavior. The angles of dilation, as affected by the abovementioned factors, are presented and discussed.

\section{Measured Volume Change Behavior of Unreinforced and Reinforced Soils}

When subject to shear stress, loose sands have been known to contract, while dense sands dilate. The volume change behavior of compacted fill is similar to that of dense sand, in a way that there is an increase in volume when subject to shear stress. The curves marked as "test 1" in Fig. 1 show the stress-strain-strength and volume change behavior of compacted granular soil without reinforcement. As in most compacted granular soils, shear-induced dilation initiates after small contraction, as indicated by an increase in volumetric strain after it passed a maximum compressive volumetric strain. Leonards [19] has used a drawing similar to Fig. 2a to illustrate the dilative behavior of dense granular soil. In dense granular soil, densely packed soil particles need to be allowed to "roll" past other particles to cause dilation. In loose granular soil, on the other hand, soil particles tend to fall into the voids between particles, assume a denser state, and cause contraction.

When geosynthetic reinforcement is introduced into a soil mass, tensile strains in the soil are inhibited by the reinforcement through soil-reinforcement interface friction. As a result, tensile loads are induced in geosynthetic reinforcement. When two adjacent layers of geosynthetic sheets are being "stretched" in tension, they form enclosed boundaries which tend to suppress dilation of the soil. This behavior can be illustrated by Fig. 2b, where two adjacent reinforcement sheets in tension are said to restrain soil particles enclosed between them from rolling past other soil particles. The illustration allows easy visualization that soil particle sizes (relative to reinforcement spacing) will have a significant effect on the behavior of GRS, which has been suggested by J. P. Giroud (cited in [26]) and verified by Wu and Pham [31]. Depending on the soil type, reinforcement spacing, and reinforcement stiffness, the presence of geosynthetic reinforcement may or may not be able to completely suppress the dilative behavior of the soil. This point will be discussed further later in this paper.

Based on measured maximum displacements of field-scale loading experiments conducted on closely spaced geosynthetic reinforced soil masses, Adams et al. [2] proposed a "zero volume change postulate" to describe measured behavior that the

(a)

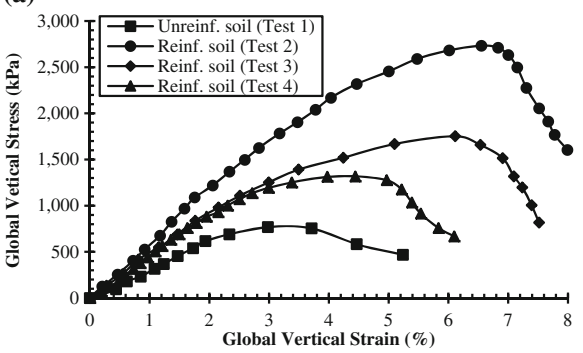

Fig. 1 Measured results of field-scale experiments: (a) stress-strain and (b) volume change behavior of unreinforced and reinforced soil masses (b)

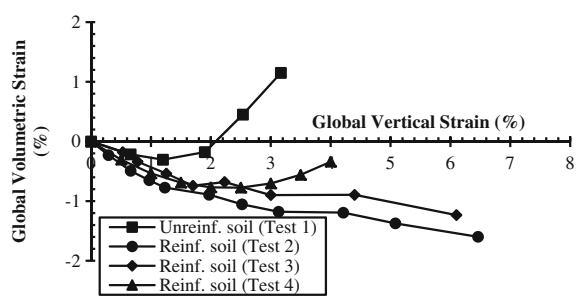




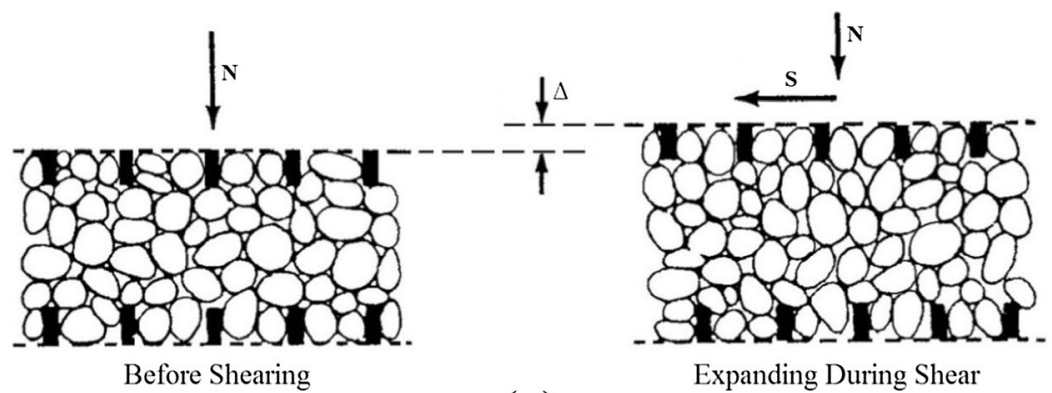

(a)

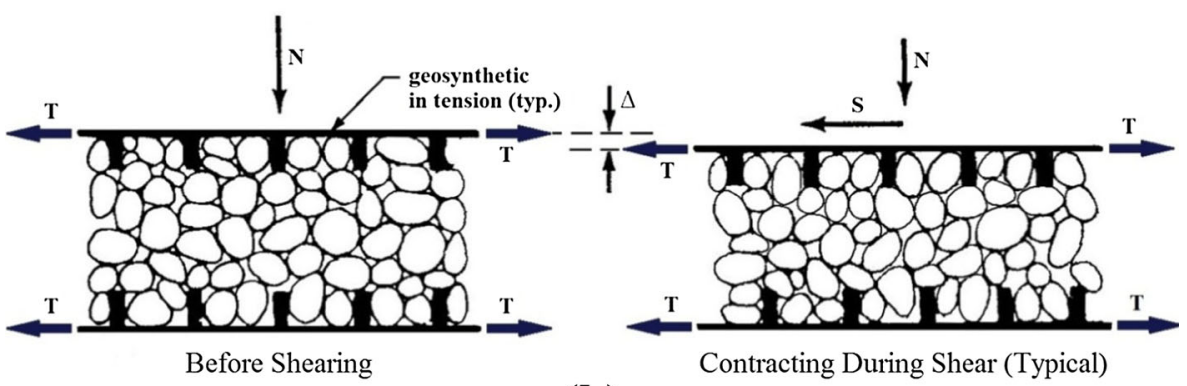

(b)

Fig. 2 Schematic diagrams of volume change behavior of compacted granular soil subject to shear stress for (a) unreinforced soil and (b) reinforced soil

vertically reduced volume is nearly the same as the laterally increased volume, i.e., there appears to be no net volume change during loading. The behavior postulated by Adams et al. [2], however, was not in agreement with the results of small triaxial tests (specimen diameter $=100 \mathrm{~mm}$ ) with inclusion of geosynthetic disks, notably those conducted by Broms [8], as shown in Fig. 3, for uniform sand in loose and dense states, with reinforcement in different configurations. The inclusion of geosynthetic disks is shown to increase the stiffness and strength of the soil, but the volume change behavior is inconsistent. Chandrasekaran et al. [9] and Haeri et al. [12] conducted similar tests, all with small triaxial test specimens. All those tests showed an increase in stiffness and strength due to inclusion of geosynthetic disks. The volume change behavior reported by Chandrasekaran et al. showed increased dilation in the reinforced specimens; on the other hand, the specimens with geosynthetic disks in the tests by Haeri et al. had decreased dilation.

It is important to point out that, with the presence of geosynthetic inclusion, a reinforced soil mass is non-uniform. For non-uniform mass, the dimensions of test specimen may be of critical importance to the validity of the test results. All soilgeosynthetic test results with volume change measurement reported in the literature have been in triaxial tests on small (100 $\mathrm{mm}$ in diameter or smaller) test specimens. The use of small specimens raises a question as to whether the test results are adequate representations of the behavior of a non-uniform soil-geosynthetic mass in the field. Moreover, compaction-induced stresses, which have been shown to have pronounced effects on GRS $[13,21,22]$ are not properly simulated in the small-scale experiments. 
(a)

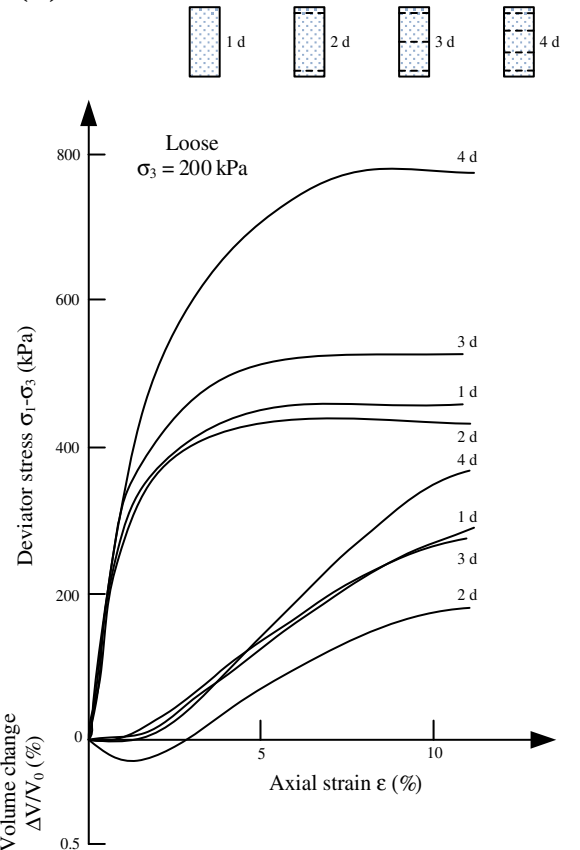

(b)
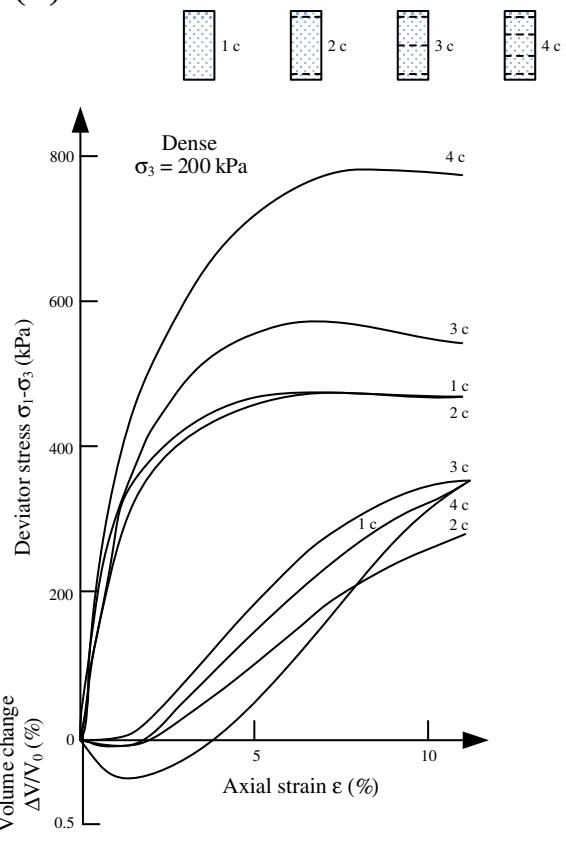

Fig. 3 Stress-strain and volumetric change relationships for unreinforced soil and reinforced soil with different layers of reinforcement, using $100 \mathrm{~mm}$ diameter specimens, for (a) loose sand and (b) dense sand [8]

To investigate the dimensions of test specimen needed to produce representative soil-geosynthetic composite behavior, a series of finite element analyses were performed $[22,31]$ by using a general purpose finite element code plaxis [23]. With a length/height ratio of 0.7 , specimen heights of 7.0, 2.0, 1.0, and $0.5 \mathrm{~m}$ under a plane strain condition were examined. The results of the analyses are shown in Fig. 4.

(a)

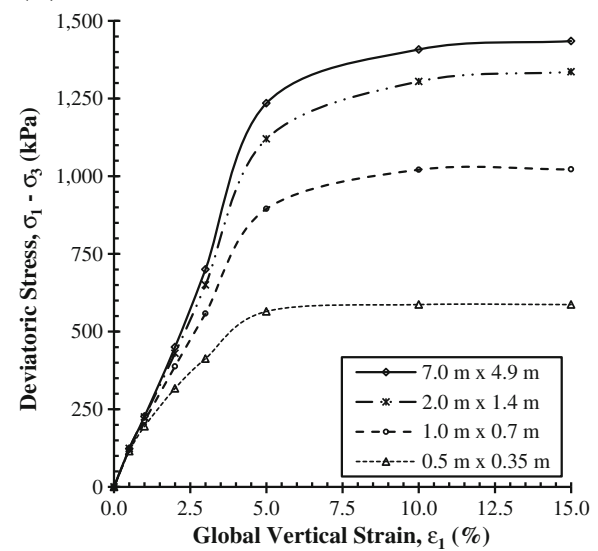

(b)

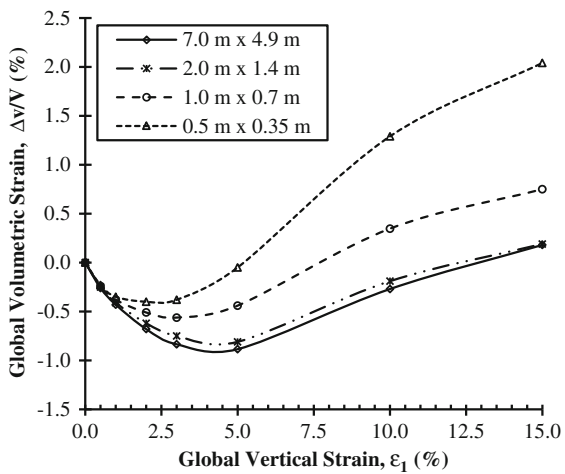

Fig. 4 (a) Stress-strain and (b) axial strain-volumetric strain relationships for soil-geosynthetic composites of different sizes 
Considering a soil-geosynthetic composite of 7.0-m high and 4.9-m wide with reinforcement spacing of $0.2 \mathrm{~m}$ as a prototype composite mass in a typical GRS wall, it is seen that specimen heights $H=1.0$ and $0.5 \mathrm{~m}$ are too small to provide an adequate representation of the prototype-reinforced soil mass and that a 2.0-m high 1.4-m long specimen will provide sufficiently accurate (within $\pm 10 \%$ deviations) representation of the stress-strain and volume change relationships. For comparison purposes, another series of finite element analyses were also performed for soil specimens without reinforcement. As shown in Fig. 5, specimen height as short as $0.5 \mathrm{~m}$ will yield nearly the same stress-strain-volume change relationships as those of uniform soil mass of $H=$ $7.0 \mathrm{~m}$ when unreinforced.

Four field-scale experiments, referred to as soil-geosynthetic composite (SGC) tests, with a specimen size of $2.0 \mathrm{~m}$ (height) by $1.4 \mathrm{~m}$ (length) by $1.2 \mathrm{~m}$ (width) have been conducted $[22,30]$, and the stress-strain strength behavior of the four SGC tests has been reported by $\mathrm{Wu}$ and Pham [31]. The experiments, with the exception of test 1 , were conducted under a confining pressure of $34 \mathrm{kPa}$ in a plane strain condition (see Fig. 6). Plane strain tests offer a better simulation of the stress conditions in typical reinforced soil walls and steepened slopes than triaxial tests. The test conditions of the four experiments are listed in Table 1. Test 1 was unreinforced; tests 2, 3, and 4

Fig. 5 (a) Stress-strain and (b) axial strain-volumetric strain relationships for soil specimens of different sizes (without reinforcement) (a)

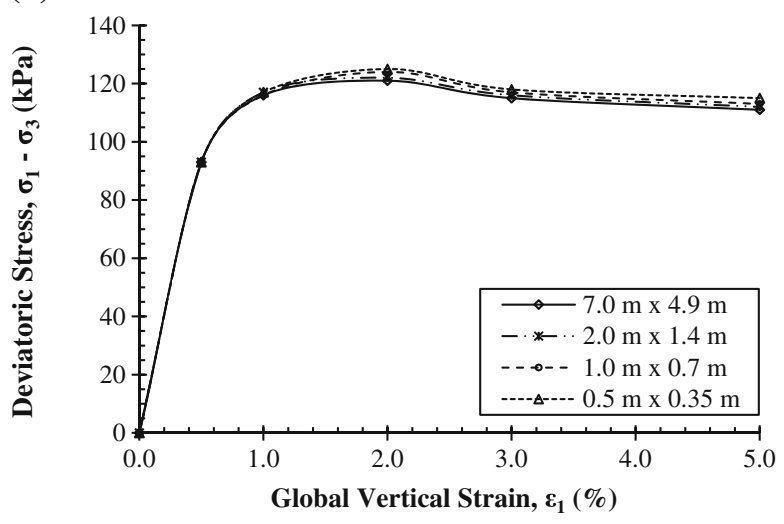

(b)

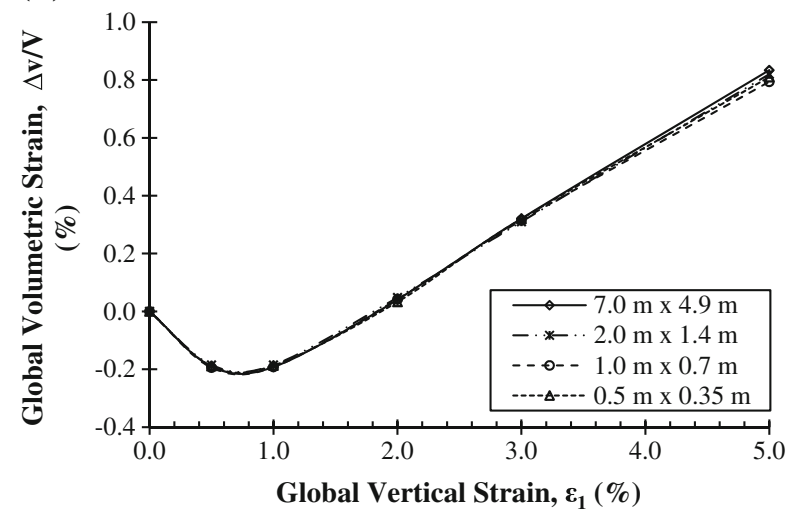


Fig. 6 Field-scale experiment of a soil-geosynthetic composite

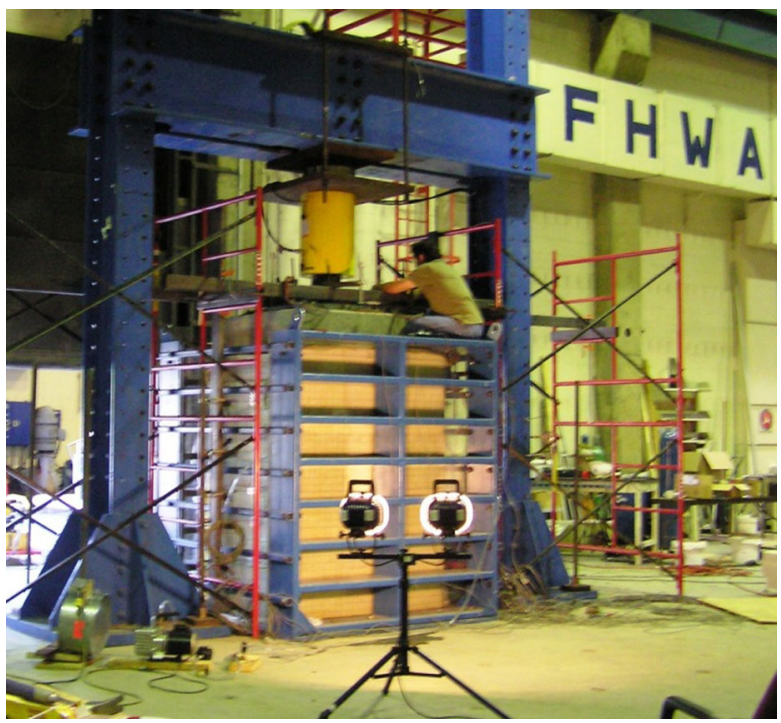

employed reinforcement spacing of 0.2 or $0.4 \mathrm{~m}$ (commonly used spacing in actual construction of closely spaced reinforced soil walls, hence the term "field-scale"). The backfill material was a crushed diabase, a well-graded gravelly soil with the largest particle size of $33 \mathrm{~mm}$, compacted to $98 \%$ per ASTM D 698. Some relevant properties of the crushed diabase include the following: specific gravity of soil solids $=3.0$, percentage of fines $=14.6 \%$, maximum dry unit weight $=24.1 \mathrm{kN} / \mathrm{m}^{3}$, and optimum water content $=5.2 \%$. In addition, five large-size $($ diameter $=152 \mathrm{~mm}$, height $=305 \mathrm{~mm})$ consolidated drained triaxial tests at different confining pressures were performed. The Mohr-Coulomb strength parameters are: $c$ (cohesion) $=70 \mathrm{kPa}, \phi$ (angle of internal

Table 1 Material parameters in finite element analysis

\begin{tabular}{|c|c|c|}
\hline Material & Material model & Parameters and values \\
\hline Soil (diabase) & Hardening model [24] & $\begin{array}{l}\text { Dry unit weight, } \gamma_{\mathrm{d}}=24 \mathrm{kN} / \mathrm{m}^{3} \text {; moist unit weight, } \\
\gamma_{\mathrm{m}}=25 \mathrm{kN} / \mathrm{m}^{3} \text {; cohesion, } c=70 \mathrm{kPa} \text {; angle of internal } \\
\text { friction, } \phi=50^{\circ} \text {; angle of dilation, } \psi=17{ }^{\circ} \text {; soil moduli } \\
\text { (as defined in [23]), } E_{50}^{\text {ref }}=63,400 \mathrm{kPa}, E_{u r}^{\text {ref }}=126,800 \mathrm{kPa} \\
E_{\text {oed }}^{\text {ref }}=54,800 \mathrm{kPa} \text {; Poisson's ratio } \nu=0.2 \text {; failure ratio, } \\
R_{\mathrm{f}}=0.9 ; \text { stress-dependency power parameter, } m=0.5\end{array}$ \\
\hline \multirow{4}{*}{$\begin{array}{l}\text { Reinforcement } \\
\quad \text { (a woven geotextile) }\end{array}$} & \multirow[t]{4}{*}{ Linear elastic model } & Test 1 no reinforcement present \\
\hline & & $\begin{array}{l}\text { Test } 2 \text { axial stiffness, EA=1,000 kN/m; ultimate strength, } \\
T_{\text {ult }}=70 \mathrm{kN} / \mathrm{m} \text {; reinforcement spacing, } S_{\mathrm{v}}=0.2 \mathrm{~m}\end{array}$ \\
\hline & & $\begin{array}{l}\text { Test } 3 \text { axial stiffness, EA=2,000 kN/m; ultimate strength, } \\
T_{\mathrm{ult}}=140 \mathrm{kN} / \mathrm{m} \text {; reinforcement spacing, } S_{\mathrm{v}}=0.4 \mathrm{~m}\end{array}$ \\
\hline & & $\begin{array}{l}\text { Test } 4 \text { axial stiffness, EA=1,000 kN/m; ultimate strength, } \\
T_{\text {ult }}=70 \mathrm{kN} / \mathrm{m} \text {; reinforcement spacing, } S_{\mathrm{v}}=0.4 \mathrm{~m}\end{array}$ \\
\hline
\end{tabular}


friction $)=50^{\circ}$ for confining pressures between 0 and $200 \mathrm{kPa}$ and $c=242 \mathrm{kPa}, \phi=38^{\circ}$ for confining pressures between 200 and $750 \mathrm{kPa}$. The geosynthetic used in the tests was a woven polypropylene geotextile. The strength property of the geotextile as provided by the manufacturer is wide width tensile strength (per ASTM D-4595)= $70 \mathrm{kN} / \mathrm{m}$ (at elongation of $10 \%$ ), in both warp and fill directions. The reinforcement of test 3 was formed by gluing two sheets of the geotextile. Tests performed on the glued specimen showed that stiffness and strength were approximately twice those of the single sheet geotextile. Details of the tests are given by Pham [22] and $\mathrm{Wu}$ et al. [30].

The measured stress-strain-strength and volume change relationships of the four field-scale tests are shown in Fig. 1. This represents the first set of field-scale test data of volume change behavior that has ever been reported. It is interesting to see that the dilative behavior exhibited in the unreinforced soil (test 1 ) is fully suppressed in test 2 $\left(\mathrm{EA}=1,000 \mathrm{kN} / \mathrm{m}, S_{\mathrm{v}}=0.2 \mathrm{~m}\right)$ and test $3\left(\mathrm{EA}=2,000 \mathrm{kN} / \mathrm{m}, S_{\mathrm{v}}=0.4 \mathrm{~m}\right)$. In test $4(\mathrm{EA}=$ $\left.1,000 \mathrm{kN} / \mathrm{m}, S_{\mathrm{v}}=0.4 \mathrm{~m}\right)$, however, dilation still occurs, although it initiates at a larger axial strain and with larger compressive volumetric strain compared to the unreinforced soil. With tests 2 and 3 having the same EA/ $S_{\mathrm{v}}$ (and $T_{\mathrm{f}} / S_{\mathrm{v}}$ ) ratio, the suppression of soil dilation only differs slightly, although the stiffness and strength of the composite was significantly greater (by a factor of 1.5 for the soil-geosynthetic composites) in test 2 $\left(S_{\mathrm{v}}=0.2 \mathrm{~m}\right)$ than in test $3\left(S_{\mathrm{v}}=0.4 \mathrm{~m}\right)$.

Comparisons of tests 3 to 4 , with EA $/ S_{\mathrm{v}}$ (and $T_{\mathrm{f}} / S_{\mathrm{v}}$ ) ratio of the former being twice the latter, reveal that (a) the volume change behaviors of the two tests are quite different and (b) the stress-strain-strength behaviors of the two tests, however, are nearly the same until the axial strain becomes larger (larger than about $2.5 \%$ in this case), after which test 3 shows higher strength than test 4 (by a factor of about 1.35). Exactly the same stress-strain-strength behavior has been observed in the field-scale experiments conducted by Adams et al. [1]. Unfortunately, no volume change behavior was measured in the experiments by Adams et al. It is interesting to note that the stressstrain and volume change behavior of a reinforced soil at smaller strains (axial strain less than $2.5 \%$ in this case) appear to be governed by reinforcement spacing; the effect of reinforcement strength only becomes significant at larger strains.

The differences in the effects on stress-strain-strength behavior and on volume change behavior, as described above, suggest that the mechanisms of apparent confining pressure and apparent cohesion (addresses strength behavior) and suppression of dilation (addresses volume change behavior) are likely independent reinforcing mechanisms.

\section{Finite Element Calibration and Analysis}

The FE method of analysis was employed to calibrate the field-scale plane strain experiments described above. The finite element program plaxis 8.2 was again selected for the analysis. The soil was simulated by a second-order hyperbolic elastoplastic hardening model by Schanz et al. [24], involving friction hardening to model the plastic shear strain in deviatoric loading and cap hardening to model the plastic volumetric strain in primary compression. The geosynthetic reinforcement was simulated by a linear elastic model. The parameters in the finite element simulation are shown in 
Table 1. The soil-reinforcement interface was assumed to be fully bonded. A detailed description of the parameters, including how they were obtained, has been given by Pham [22].

Past experience with finite element analysis conducted by other researchers (e.g., $[13,21])$ has indicated that the effect of residual (lock-in) lateral stress due to fill compaction needs to be accounted for in the analysis of reinforced soil structures. Wu and Pham [29] reasoned that this might be due to the fact that frictional resistance along soil-geosynthetic interface tends to restrain lateral deformation of the soil hence resulting in a significantly higher residual stress due to fill compaction. The residual lateral stress in a GRS mass due to compaction, $\Delta \sigma_{3}$, in this study was evaluated by the following equation [29]:

$$
\Delta \sigma_{3}=\Delta \sigma_{c, \max } \quad K_{i, c} F\left(1+\frac{0.7 E_{r}}{E_{s} S_{v}-0.7 E_{r}}\right)
$$

where $\Delta \sigma_{c, \max }$ is the maximum vertical stress due to fill compaction; $K_{i, c}$ is the coefficient of lateral earth pressure of a GRS mass in initial loading; $F=1-\frac{\left(O C R-O C R^{\sin \varphi}\right)}{O C R-1} ; E_{\mathrm{s}}$ and $E_{\mathrm{r}}$ are soil stiffness and reinforcement stiffness, respectively; and $S_{\mathrm{v}}$ is reinforcement spacing. The explanations of how to obtain the model parameters in Eq. (1) have been given by Pham [22] and Wu and Pham [29]. The finite element analysis was carried out by following closely the construction procedure for specimen preparation of the SGC tests. Compaction of each soil lift was simulated by applying a uniform equivalent compaction pressure of $44 \mathrm{kPa}$ (calculated for the specific plate compactor used in the SGC tests) over the entire surface of the newly placed soil layer and removing it before the placement of the next reinforcement layer.

The stress-strain and volume change relationships for tests 2, 3, and 4 obtained from the FE analysis, along with measured test results, are shown in Fig. 7. It is seen that the stress-strain and volume change curves obtained from FE analysis are in good agreement with measured data.

The extent of reduction in volume change due to geosynthetic reinforcement may be expressed quantitatively in terms of the angle of dilation. The angle of dilation, $\psi$, is a measure of the change in volumetric strain with respect to the change in shear strain; $\psi$ has commonly been defined as:

$$
\sin \psi=-\frac{d \varepsilon_{v}}{d \gamma}=\frac{d \varepsilon_{1}+d \varepsilon_{2}+d \varepsilon_{3}}{d \varepsilon_{1}-d \varepsilon_{3}}
$$

in which $\varepsilon_{\mathrm{v}}$ is volumetric strain, $\gamma$ is shear strain, and $\varepsilon_{1}, \varepsilon_{2}$, and $\varepsilon_{3}$ are the principal strains. For the measured results shown in Fig. 1, the angle of dilation $\psi$ of the unreinforced soil is approximately $+4^{\circ}$ from the point of maximum compressive volumetric strain (or axial strain of about 1.3 to $2.0 \%$ ) and increases to about $+20^{\circ}$ thereafter. For the reinforced soil, the dilation angle $\psi$ was about $-4,-4$, and $+7^{\circ}$ for tests 2,3 , and 4 , respectively. The reported $\psi$ values are evaluated as the increment of volumetric strain corresponding to an increase in axial strain becomes essentially constant. Note that a positive dilation angle indicates expansion, and a negative dilation angle indicates contraction. 


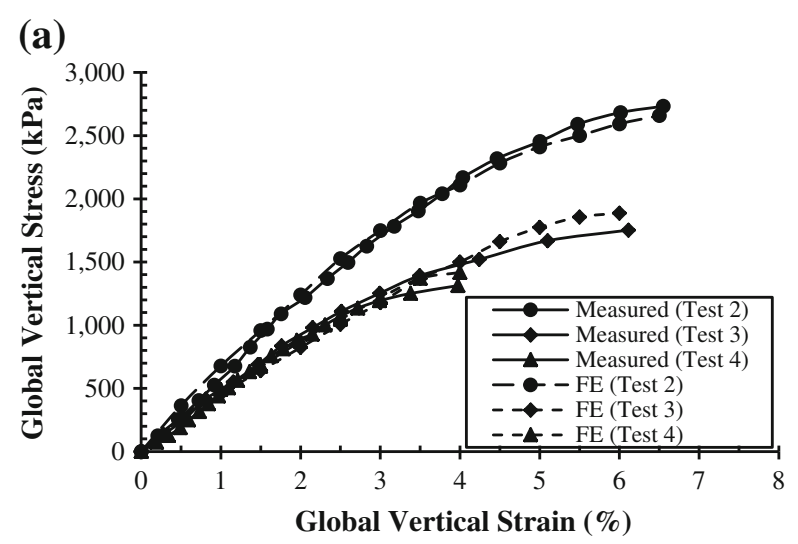

(b) Global Vertical Strain (\%)

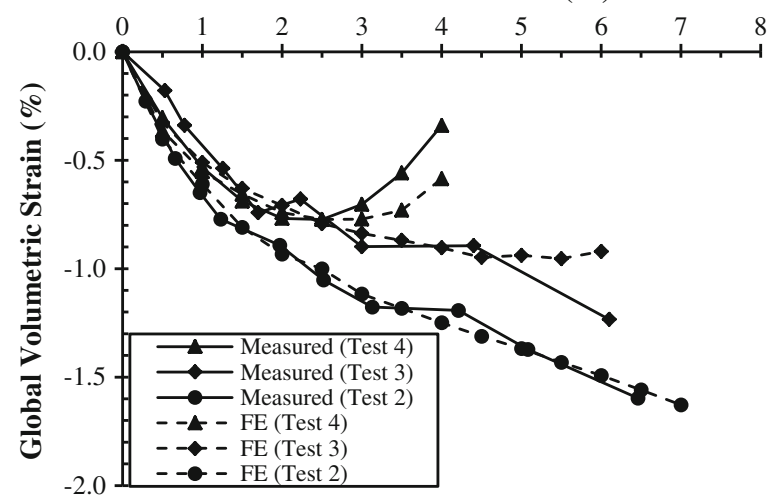

Fig. 7 Measured vs. simulated (a) stress-strain and (b) volume change behaviors of reinforced soil mass

\section{Parametric Study}

Using the calibrated finite element model, it is interesting to examine how the dilative behavior is affected by reinforcement spacing, reinforcement stiffness, and soil stiffness. A preliminary parametric study based on the calibrated parameters was performed for this purpose. For the parametric study, the geometry and material parameters of test 2 (see Table 1) were used as the baseline. When the effect of a certain factor was being examined, all other material parameters were held the same as those of the baseline case.

\section{Effect of Reinforcement Spacing}

The effect of reinforcement spacing $\left(S_{\mathrm{v}}\right)$ on volume change behavior of soilgeosynthetic composites is of great interest in light of the very significant benefit of small reinforcement spacing on stress-strain-strength behavior (which has been demonstrated by [31]). The effect was examined by changing the spacing of $0.2 \mathrm{~m}$ in the baseline case to $0.1,0.5$, and $1.0 \mathrm{~m}$. The resulting volume change behavior is shown in Fig. 8. It is seen that reinforcement spacing has a strong effect on the volume change 


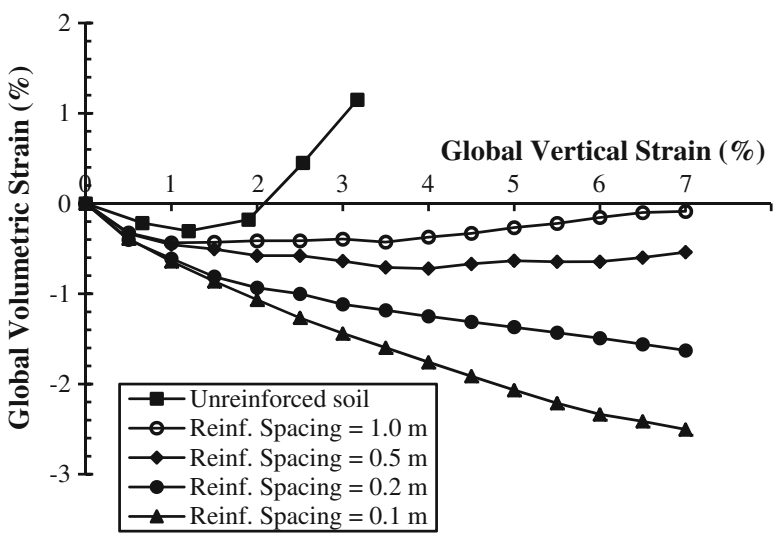

Fig. 8 Volume change behavior of soil-geosynthetic composites of different values of reinforcement spacing

behavior. For $S_{\mathrm{v}}=1.0 \mathrm{~m}$, the soil dilation is seen to be much less than that of the unreinforced soil. For $S_{\mathrm{v}}=0.5 \mathrm{~m}$, the composite becomes nearly incompressible (i.e., no volume change) as axial strain exceeds about $2 \%$. For $S_{\mathrm{v}}=0.2$ and $0.1 \mathrm{~m}$, dilation of the composites is suppressed over the entire range of stress/strain investigated, with the extent of contraction being stronger for $S_{\mathrm{v}}=0.1 \mathrm{~m}$ than that for $S_{\mathrm{v}}=0.2 \mathrm{~m}$.

The dilation angles for reinforcement spacing of $0.1,0.2,0.5$, and $1.0 \mathrm{~m}$ and unreinforced soil are determined to be $-10,-3.5,0,+3$, and $+20^{\circ}$, respectively (a smaller negative $\psi$ value indicating more contraction and implying fewer tendencies for dilation). Figure 9a shows how reinforcement spacing affects dilation angle of the soilgeosynthetic composites. When the inverse of reinforcement spacing increases from 0 to 10 (i.e., reinforcement spacing decreases from $\infty$, i.e., unreinforced to $0.1 \mathrm{~m}$ ), the corresponding dilation angle $\psi$ gradually decreases from +20 to $-10^{\circ}$, with $S_{\mathrm{v}}=0.5 \mathrm{~m}$ showing near-incompressible behavior. Note that the relationship can be approximated by two straight lines with an inflection point around $S_{\mathrm{v}}=0.65 \mathrm{~m}\left(\right.$ or $\left.1 / S_{\mathrm{v}}=1.5 \mathrm{~m}^{-1}\right)$ for the set of parameters employed in this study. The inflection point between ultimate strength of the soil-geosynthetic composites and reinforcement spacing occurs around $S_{\mathrm{v}}=0.5 \mathrm{~m}$, as seen in Fig. 9b. The correlation between Fig. 9a, b again suggests that the mechanisms of apparent confining pressure and apparent cohesion (addresses strength of soil-geosynthetic composites) and the mechanism of suppressing soil dilation (addresses volume change of soil-geosynthetic composites), although related, are likely different.

Of note, the inflection points of 0.5 and $0.65 \mathrm{~m}$ may signify the boundary of composite behavior of GRS for the parameters investigated in this study. The boundary criteria of GRS are of important practical significance. Further study will be needed to investigate this issue.

\section{Effect of Reinforcement Stiffness}

The effect of reinforcement stiffness on volume change behavior of soil-geosynthetic composites was examined by halving, doubling, and quadrupling the value of reinforcement stiffness (EA) in the baseline case of $1,000 \mathrm{kN} / \mathrm{m}$. The stiffness values investigated were $500,1,000,2,000$, and $4,000 \mathrm{kN} / \mathrm{m}$, and the volume change behavior 
Fig. 9 Effects of reinforcement spacing on a angle of dilation and $\mathbf{b}$ ultimate strength of soilgeosynthetic composites

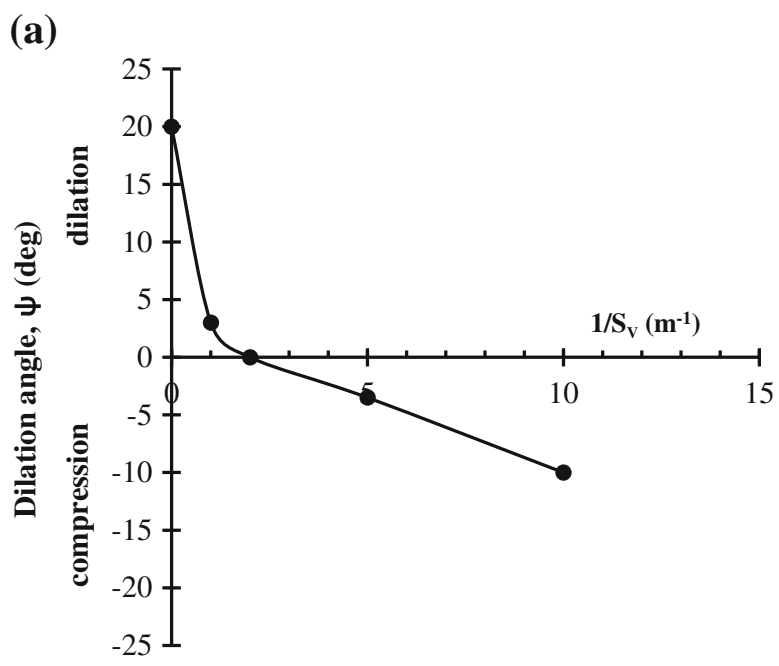

(b)

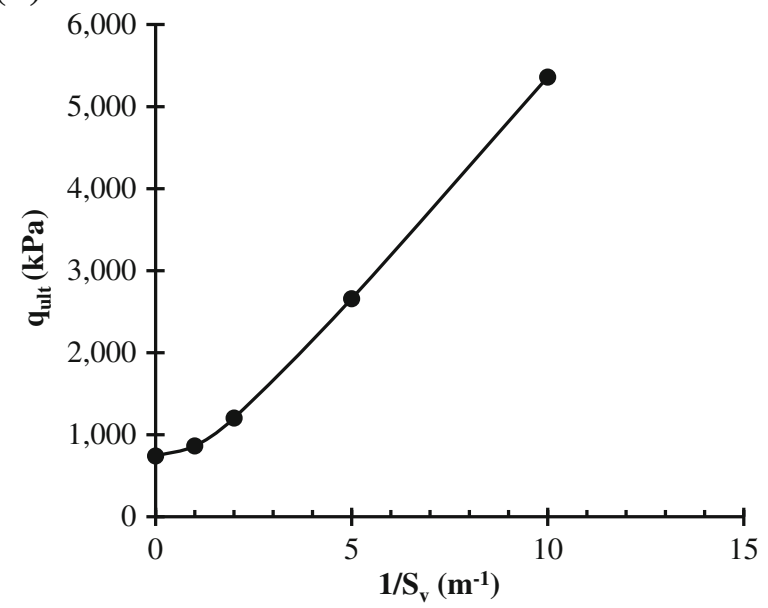

is shown in Fig. 10. With these reinforcement stiffness values, while maintaining reinforcement spacing of $0.2 \mathrm{~m}$, all the soil-reinforcement composites contract when subject to shear. The effect of reinforcement stiffness is seen to be modest. The angles of dilation $\psi$ corresponding to EA of $500,1,000,2,000$, and 4,000 $\mathrm{kN} / \mathrm{m}$ are $-2.5,-4$, -10 , and $-12.5^{\circ}$, respectively.

\section{Effect of Soil Stiffness}

The stiffness of soil for the second-order hyperbolic elastoplastic hardening model is characterized by a number of parameters. To examine the effects of soil stiffness on the volume change behavior of soil-geosynthetic composites, only the value of the reference stiffness modulus $\left(E_{50}^{\text {ref }}\right)$ was varied. The value of $E_{50}^{\text {ref }}$ in the baseline case was halved and doubled, and the resulting volume change curves are shown in Fig. 11. As to be expected, a higher value of soil stiffness modulus results in smaller volumetric 


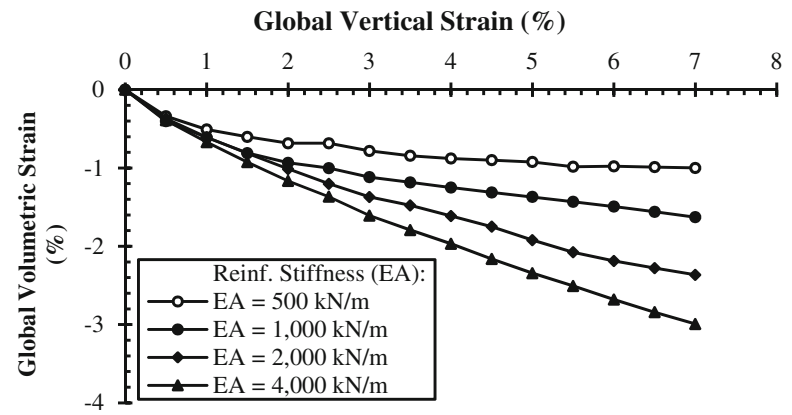

Fig. 10 Volume change behavior of soil-geosynthetic composites of different values of reinforcement stiffness

strain. For the higher soil stiffness modulus, the volumetric change becomes negligible at volumetric strain of about $0.5 \%$, and the angle of dilation $\psi=0$. For the baseline case $\left(E_{50}^{r e f}=63,400 \mathrm{kPa}\right)$, the soil-geosynthetic composite shows more contraction, with $\psi=$ $-4{ }^{\circ}$. For the lower soil stiffness modulus, the soil-geosynthetic composite is seen to contract more, with $\psi=-10^{\circ}$.

\section{Summary and Concluding Remarks}

The presence of geosynthetic reinforcement in closely spaced soil mass can serve to suppress soil dilation and lead to a stronger soil, as evidenced by field-scale experiments and finite element analysis presented in this paper. Factors such as reinforcement spacing, soil stiffness, and reinforcement stiffness are shown to affect the extent of suppression of soil. Measured results of the field-scale tests (Fig. 1) and finite element analysis results (Fig. 9) suggests that the mechanisms of apparent confining pressure and apparent cohesion (addresses strength behavior) and the mechanism of suppressing soil dilation (addresses volume change behavior), although related, are likely different.

The angle of dilation of a soil-geosynthetic composite appears to be a viable parameter to characterize the degree of suppression of dilation in a quantitative manner. A smaller dilation angle typically results in smaller deformations/movements of an earth structure, as has been shown by a number of examples given by Houlsby [15]. For actual applications, it may be feasible to conduct a simple soil-geosynthetic interactive

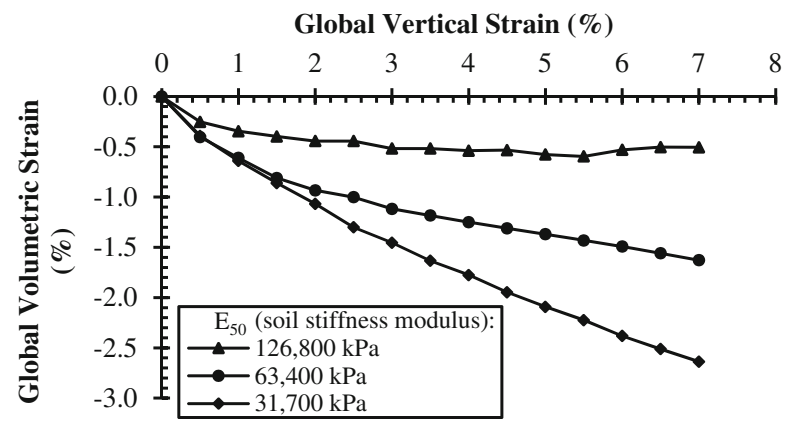

Fig. 11 Volume change behavior of soil-geosynthetic composites of different values of soil stiffness 
performance test $[17,18,28]$ with prescribed soil and reinforcement prepared under conditions replicating the anticipated field placement conditions, measure volume change behavior of the soil-geosynthetic composite, and determine the angle of dilation to access the reinforcing effect of the soil-geosynthetic composite.

It is important to note that, due to the presence of geosynthetic reinforcement, a soilgeosynthetic composite is not a uniform mass. Therefore, field-scale experiments are needed for investigation of the volume change behavior of geosynthetic-reinforced soil. Reduced-scale experiments can lead to inaccurate or even misleading behavior. Also, the zero volume change postulate (i.e., $\psi=0$ ), which has been adopted by the FHWA GRS-IBS for evaluation of maximum lateral strain of a GRS bridge abutment [3], will result in conservative estimate of maximum lateral deformation if the dilative behavior of the soil is suppressed (i.e., $\psi<0$ for the soil-geosynthetic composite), which occurs when reinforcement spacing is $0.5 \mathrm{~m}$ or less for the parameters employed in this study.

Acknowledgments The lead author wishes to acknowledge the contribution of Michael Adams of the Federal Highway Administration, whose expertise in GRS and large-scale experiments made the field-scale experiments of soil-geosynthetic composites possible.

\section{References}

1. Adams, M.T., Ketachart, K., Wu, J.T.H.: Mini pier experiments - geosynthetic reinforcement spacing and strength as related to performance. Proceedings, Geo-Denver 2007, ASCE, Denver, (2007)

2. Adams, M.T., Lillis, C.P., Wu, J.T.H., Ketchart, K.: Vegas mini pier experiment and postulate of zero volume change. Proceedings, seventh international conference on geosynthetics, Nice, France, pp. 389394 (2002)

3. Adams, M.T., Nicks, J., Stabile, T., Wu, J.T.H., Schlatter, W., Hartmann, J.: Geosynthetic reinforced soil integrated bridge system-interim implementation guide. Report no. FHWA-HRT-11-026, Federal Highway Administration, McLean, VA (2011a)

4. Adams, M.T., Nicks, J., Stabile, T., Wu, J.T.H., Schlatter, W., Hartmann, J.: Geosynthetic reinforced soil integrated bridge system-synthesis report. Report no. FHWA-HRT-11-027, Federal Highway Administration, McLean, VA (2011b)

5. Athanasopoulos, G.A.: Effect of particle size on the mechanical behavior of sand-geotextile composite. Geotext. Geomembr. 12, 255-273 (1993)

6. Bao, C.: Study on the interaction behavior of geosynthetics and soil in China. Proceedings of GeoAsia 2004 conference, third Asian regional conference on geosynthetics, Seoul, Korea, pp. 104-115 (2004)

7. Bassett, A.K., Last, N.C.: Reinforcing earth below footings and embankments. Proceedings, ASCE spring convention and exhibit, Pittsburgh, PA (1978)

8. Broms, B.B.: Triaxial tests with fabric-reinforced soil. Proceedings, international conference on use of fabrics in geotechnics, L'Ecole nationale des ponts et chaussees, vol. Ill, Paris, France, 1977, pp. 129-133 (1977)

9. Chandrasekaran, B., Broms, B.B., Wong, K.S.: Strength of fabric reinforced sand under axisymmetric loading. Geotext. Geomembr. 8(4), 293-310 (1989)

10. Elton, D.J., Patawaran, M.A.B..: Mechanically stabilized earth reinforcement tensile strength from tests of geotextile-reinforced soil. Journal of the Transportation Research Board, no. 1868, TRB, National Research Council, Washington, D.C., pp. 81-88 (2004)

11. Gray, D.H., Al-Refeai, T.: Behavior of fabric- versus fiber-reinforced sand. ASCE J. Geotech. Eng. 112(8), 804-820 (1986)

12. Haeri, S.M., Noorzad, R., Oskoorouchi, A.M.: Effect of geotextile reinforcement on the mechanical behavior of sand. Geotext. Geomembr. 18(6), 385-402 (2000)

13. Hatami, K., Bathurst, R.J.: Numerical model for reinforced soil segmental walls under surcharge loading. ASCE J. Geotech. Geoenviron. Eng. 132(6), 673-684 (2006)

14. Hausmann, M.R.: Strength of reinforced earth. Proceedings, $8^{\text {th }}$ Australian Road Research Conference, 8(13), 1-8 (1976) 
15. Houlsby, G.T.: How the dilatancy of soils affect their behaviour. 10th European conference on soil mechanics and foundation engineering, Florence, Italy (1991)

16. Ingold, T.S.: Reinforced earth. Thomas Telford Ltd, London (1982)

17. Ketchart, K., Wu, J.T.H.: Performance test for geosynthetic-reinforced soil including effects of preloading. FHWA-RD-01-018, Turner-Fairbank Highway Research Center, 270 p. (2001)

18. Ketchart, K., Wu, J.T.H.: A modified soil-geosynthetic interactive performance test for evaluating deformation behavior of GRS structures. ASTM Geotech. Test. J. 25(4), 405-413 (2002)

19. Leonards, G.A.: Foundation engineering, chapter 2: engineering properties of soils. McGraw-Hill, New York (1962)

20. Maher, M.H., Woods, R.D.: Dynamic response of sand reinforced with randomly distributed fibers. ASCE J. Geotech. Eng. 116, 1116-1131 (1990)

21. Morrison, K.F., Harrison, F.E., Collin, J.G., Dodds, A., Arndt, B.: Shored mechanically stabilized earth (SMSE) wall systems design guidelines. Report FHWA-CFL/TD-06-001, Federal Highway Administration, Lakewood, Colorado, 210 p (2006)

22. Pham, T.Q.: Investigating composite behavior of geosynthetic-reinforced soil (GRS) mass. Ph.D. Dissertation, University of Colorado Denver (2009)

23. Plaxis, B.V.: Plaxis 2D-version 8 manual. Balkema Publisher, Rotterdam (2002)

24. Schanz, T., Vermeer, P.A., Bonnier, P.G.: The hardening soil model: formulation and verification. Beyond 2000 in computational geotechnics, 10 years of PLAXIS, Balkema Publisher, Rotterdam, pp. 1-16 (1999)

25. Schlosser, F., Long, N.C.: La terre armée dans l'échangeur de Sète, Rev. Générale des Routes (480) (1972)

26. VanBuskirk, C.: Adoption and implementation of GRS design concepts - a consultant's perspective. 19th Vancouver Geotechnical Society Symposium, Geosynthetic Reinforced Walls, Slopes, and Earthworks, May 2010 (2010)

27. Wu, J.T.H.: Revising the AASHTO guidelines for design and construction of GRS walls. Colorado Department of Transportation, Report no. CDOT-DTD-R-2001-16. 148 p. (2001)

28. Wu, J.T.H., Adams, M.: Myths and facts on long-term creep of GRS structures. geosynthetics in reinforcement and hydraulic application, Geo-Denver 2007: new peaks in geotechnics, American Society of Civil Engineers, pp. 1-12 (2007)

29. Wu, J.T.H., Pham, Q.: An analytical model for evaluation of compaction-induced stresses in geosyntheticreinforced soil (GRS) mass. Int. J. Geotech. Eng. 4(4), 549-556 (2010)

30. Wu, J.T.H., Pham, T.Q., Adams, M.T.: Composite behavior of geosynthetic-reinforced soil (GRS) mass. Final report to the Federal Highway Administration, January, 277 p (2010)

31. Wu, J.T.H., Pham, T.Q.: Load carrying capacity and required reinforcement strength of closely spaced soil-geosynthetic composites. ASCE J. Geotech. Geoenviron. Eng. (2013). doi:10.1061/(ASCE)GT.19435606.0000885

32. Yang, Z.: Strength and deformation characteristics of reinforced sand. Ph.D. dissertation, University of California at Los Angeles (1972)

33. Ziegler, M., Heerten, G., Ruiken.G.: Progress in the understanding of geosynthetic/soil composite material behaviour in geosynthetic reinforced earth structures, First Pan American geosynthetics conference \& exhibition, Cancun, Mexico (2008) 